\title{
Bioethanol Production from Molasses by Yeasts with Stress-Tolerance Isolated from Aquatic Environments in Japan
}

\author{
Yuka Naito', Masahiko Okai1 ${ }^{1}$, Masami Ishida ${ }^{1}$, Masachika Takashio ${ }^{2}$, Naoto Urano ${ }^{1 *}$ \\ ${ }^{1}$ Laboratory of Marine Biochemistry, Department of Ocean Sciences, Tokyo University of Marine Science and Technology, Konan, \\ Minato-ku, Tokyo, Japan \\ ${ }^{2}$ Zensho Laboratories of Food Technology, Zensho Holdings Co. Ltd., Konan, Minato-ku, Tokyo, Japan \\ Email: *urano@kaiyodai.ac.jp
}

How to cite this paper: Naito, Y., Okai, M., Ishida, M., Takashio, M. and Urano, N. (2019) Bioethanol Production from Molasses by Yeasts with Stress-Tolerance Isolated from Aquatic Environments in Japan. Advances in Microbiology, 9, 1000-1011. https://doi.org/10.4236/aim.2019.912065

Received: November 27, 2019

Accepted: December 20, 2019

Published: December 23, 2019

Copyright $\odot 2019$ by author(s) and Scientific Research Publishing Inc. This work is licensed under the Creative Commons Attribution International License (CC BY 4.0).

http://creativecommons.org/licenses/by/4.0/

\begin{abstract}
Bioethanol is a safe and renewable source of energy that continues to be a research focus, since fossil fuels have been linked to global warming and nuclear energy sources are affected by the increased safety concerns following the 2011 nuclear power plant accident in Japan. In general, bioethanol is converted from a biomass by yeast fermentation. The production efficiency of this bioethanol is not sufficiently high, and its practical use as a substitute for fossil fuels and nuclear energy is thus limited. For the industrial production of bioethanol, the yeast fermentation of biomass cultures containing high concentration sugar, $\mathrm{NaCl}$, and ethanol is necessary, but this might induce phenomena in which the stresses arising in the yeasts weaken their cells during fermentation. As described herein, we isolated 1028 strains of yeasts from natural aquatic environments: Japan's Tama River and Lake Kasumigaura. Among them, 412 strains were fermentative yeasts and 31 strains showed high fermentation ability under a $30 \%$ sorbitol $+10 \%$ ethanol condition. These strains were identified as Torulaspola delbrueckii, Wickerhamomyces anomalus, Candida glabrata, Pichia kudriavzevii, Saccharomyces cf. cerevisiael paradoxus, and Lachancea kluyveri. The strains T. delbrueckii, W. anomalus, and C. glabrata also showed tolerance against $15 \% \mathrm{NaCl}$. Most importantly, S. cf. cerevisiael paradoxus $\mathrm{H} 28$ and L. kluyveri F2-67 produced 57.4 $\mathrm{g} / \mathrm{L}$ and $53.9 \mathrm{~g} / \mathrm{L}$ ethanol from molasses (sucrose $104.0 \mathrm{~g} / \mathrm{L}$, fructose $33.4 \mathrm{~g} / \mathrm{L}$, and glucose $24.8 \mathrm{~g} / \mathrm{L}$ ) within $48 \mathrm{hrs}$ at $25^{\circ} \mathrm{C}$, respectively.
\end{abstract}

\section{Keywords}

Stress-Tolerance, Molasses, Yeast Species, Aquatic Environment, Fermentation 


\section{Introduction}

Yeasts have been used for many decades in a wide range of industries, including the production of food and ethanol. In recent years, bioethanol has attracted attention as a source of clean energy and as an alternative to the fossil fuels linked to global warming and the nuclear energy accompanied by heightened safety concerns after the 2011 nuclear power plant accident in Japan. Generally, bioethanol is converted from a biomass by yeast fermentation. There are several types of biomass that can be used to make ethanol, including sugar cane, corn, and their residual substances; molasses from land plants, and marine biomass from seaweeds. Bioethanol is considered a renewable source of energy because biomasses are permanent resources that can be continuously produced and renewed [1] [2].

However, the production of bioethanol from a biomass with the use of yeasts is not sufficiently high, and thus the practical use of bioethanol instead of the fossil fuels and nuclear energy has been limited. For the industrial production of bioethanol, it is necessary to establish the optimal methods for the yeast fermentation of biomass cultures that contain high concentrations of salt, sugar, and ethanol. However, such methods might induce phenomena in which the stresses arising in the yeasts weaken their cells during fermentation. We have thus been investigating various types of stress-resistant yeasts isolated from aquatic environments. We have isolated thermotolerant, fermentative yeasts from hot spring drainage [3] [4] [5] [6] and have produced bioethanol from highly concentrated saccharified suspensions of water hyacinth [7] [8], paper shredder scrap [9], and seaweed [10] [11] [12]. We also characterized salt-tolerant yeasts [13] and yeasts that are tolerant to specific types of pressure [14].

In industrial-scale bioethanol production, the sugar concentration of the molasses used is often $>40 \%$ [15], and yeasts that have fermentative ability are required under high stress and high pressure. Toward the goal of producing bioethanol from molasses, we conducted the present study to identify highly fermentative yeasts with tolerances against salt, sugar and ethanol stresses.

\section{Materials and Methods}

\subsection{Yeast Isolation}

For the isolation of yeasts, we obtained samples from 12 stations: at Stations 1 - 3 from the midstream of Tama River on July 12, 2017; at Stations 4 - 6 from the downstream of Tama River on May 11, 2017; at Stations 7 - 9 from the estuary of Tama River in Tokyo on August 21, 2017; and at Stations 10 - 12 from Lake Kasumigaura in Ibaraki Prefecture on October 11, 2017. To obtain these samples, we collected mud sediment from the aquatic environments with the use of an Ekman-Birge Grab sampler (Miyamoto Riken Industry Co., Osaka, Japan) except at Stn. 9, where we collected seawater. The sample was collected from bottom of depth $1-10 \mathrm{~m}$ at each sampling site and immediately transferred to sterilized plastic bottles that were maintained at low temperature while they were carried to our laboratory at the Tokyo University of Marine Science and Tech- 
nology. Each sample was diluted to 10 or 100 times with saline. Aliquots (200 $\mu \mathrm{L}$ ) of diluted samples were spread on YPD solid medium (D-glucose, $20 \mathrm{~g} / \mathrm{L}$; peptone, $20 \mathrm{~g} / \mathrm{L}$; yeast extract, $10 \mathrm{~g} / \mathrm{L}$; chloramphenicol, $0.2 \mathrm{~g} / \mathrm{L}$; agar, $20 \mathrm{~g} / \mathrm{L}$ ) and incubated for approx. $72 \mathrm{hrs}$ at $25^{\circ} \mathrm{C}$. Each growing yeast-like colony was picked up, and the isolation of its microorganisms was performed. We also measured the pH with HORIBA Scientific F-71S (HORIBA, Ltd., Kyoto, Japan), NaCl concentration with HORIBA Scientific B-721 (HORIBA, Ltd.) and water temperature of each sampling area.

\subsection{Assay of Yeast Fermentative and Tolerant Activities under Sorbitol and Ethanol}

We assayed the fermentative and tolerant activities of each yeast strain under sorbitol and ethanol with a five-step screening, as follows. 1) The yeast fermentation activity with YPD liquid medium under stress-free conditions was assayed; 2) Using strains selected in the first screening, we evaluated the effect of sugar osmotic stress on the fermentative yeasts in experiments using the YPD liquid medium containing 30\% (w/v) sorbitol; 3) Using strains selected in the second screening, we determined the effect of ethanol on the fermentative yeasts by using the YPD liquid medium containing $10 \%(\mathrm{v} / \mathrm{v})$ ethanol; 4) Using strains selected in the third screening, we investigated the effects of sorbitol and ethanol on the fermentative yeasts by using the YPD liquid medium containing $20 \%$ $(\mathrm{w} / \mathrm{v})$ sorbitol and $10 \%(\mathrm{v} / \mathrm{v})$ ethanol; 5) With the strains selected in the fourth screening, we used the YPD liquid medium containing $30 \%(\mathrm{w} / \mathrm{v})$ sorbitol and $10 \%(\mathrm{v} / \mathrm{v})$ ethanol in fermentation experiments.

The fermentation was carried out in test tubes covered with aluminum caps for 2 weeks at $25^{\circ} \mathrm{C}$. The screening of fermentative yeasts was conducted using inverted Durham pipes for the visualization of the $\mathrm{CO}_{2}$ production.

\subsection{Yeast Identification}

The 26S rDNA D1/D2 domain of each highly fermentative yeast identified as described above in Section 2.2 were amplified by polymerase chain reactions (PCRs) using the forward primer NL-1 (5'-GCATATCAATAAGCGGAGGAAAAG-3') and the reverse primer NL-4 (5'-GGTCCGTGTTTCAAGACGG-3'), and Premix Ex Taq (Takara Bio, Shiga, Japan). The PCR program was performed with an initial denaturation at $95^{\circ} \mathrm{C}$ for $5 \mathrm{~min}$, followed by 25 cycles of denaturation at $94^{\circ} \mathrm{C}$ for $30 \mathrm{~s}$, annealing at $56^{\circ} \mathrm{C}$ for $30 \mathrm{~s}$, extension at $72^{\circ} \mathrm{C}$ for $1 \mathrm{~min}$ and final extension at $72^{\circ} \mathrm{C}$ for $4 \mathrm{~min}$ in a TaKaRa PCR Thermal Cycler Dice. Sequences were analyzed using the BLAST function at the U.S. NCBI website (http://www.ncbi.nlm.nih.gov/blast). The D1/D2 domain sequences of the 26S rDNA genes in the yeasts were deposited in DDBJ.

\subsection{Assay of Yeast Salinity Tolerance}

We assessed the effect of salinity on the fermentative yeasts identified as described above in Section 2.3. The YPD liquid medium containing 5.0\%, 10.0\%, 
$15.0 \%$, or $20.0 \%(\mathrm{w} / \mathrm{v}) \mathrm{NaCl}$ was used in the fermentation experiments. Fermentation was carried out for 2 weeks at $25^{\circ} \mathrm{C}$, and the fermentative yeasts were screened using the same method as that described in Section 2.2.

\subsection{Assay of Ethanol Productivity by the Yeasts}

We investigated the ethanol productivity of each of the identified yeasts. Each yeast strain was aerobically precultured with stirring at $120 \mathrm{rpm}$ for $48 \mathrm{hrs}$ at $25^{\circ} \mathrm{C}$ in $10 \mathrm{~mL}$ of YPD liquid medium. The growing yeast was centrifuged at $3000 \mathrm{rpm}$ for $5 \mathrm{~min}$, and its precipitate was washed with saline. The centrifugation/washing procedure was conducted three times, and the cells were obtained. Then, $0.3 \mathrm{~g}$ of yeast pellet was anaerobically cultured for $20 \mathrm{hrs}$ at $25^{\circ} \mathrm{C}$ in $10 \mathrm{~mL}$ of YPD liquid medium with the use of an anaero Pack System (Mitsubishi Gas Chemical Co., Tokyo, Japan). The ethanol production of each yeast strain was determined by an Ethanol F-kit (Roche Diagnostics, Indianapolis, IN, USA).

\subsection{Assay of Sugar Consumption and Ethanol Productivity from Molasses by the Yeast}

Molasses was purchased from Alishan Co. (Tokyo, Japan). We evaluated the sugar consumption and the ethanol productivity of each species' representative yeast from diluted molasses. Representative strains were selected based on the results of the procedures described in Sections 2.4 and 2.5. Each yeast was aerobically precultured for $48 \mathrm{hrs}$ at $25^{\circ} \mathrm{C}$, with stirring at $120 \mathrm{rpm}$ in $10 \mathrm{~mL}$ of YPD liquid medium including $1.0 \mathrm{M}$ glucose. The growing yeast was centrifuged at $3000 \mathrm{rpm}$ for $5 \mathrm{~min}$, and its precipitate was washed with saline. The centrifugation/washing procedure was conducted three times, and the cells were obtained. Then, $0.3 \mathrm{~g}$ of yeast pellet was anaerobically cultured for $48 \mathrm{hrs}$ at $25^{\circ} \mathrm{C}$ in $25 \%$ (w/v) diluted molasses with an anaero Pack System. The sugar consumption and ethanol production of the selected yeasts were determined with a Sucrose/D-glucose/ D-Fructose F-kit (Roche Diagnostics) and Ethanol F-kit (Roche Diagnostics).

\section{Results}

\subsection{The Isolation of Environmental Yeasts}

We selected two sampling sites, Tama River and Lake Kasumigaura, where a large quantity of domestic wastewater flowed into, for the isolation of a variety species of yeasts. Figure 1 illustrates the sampling sites of Tama River and its tributaries flowing between Tokyo and Kanagawa Prefecture and the sampling sites of Lake Kasumigaura in Ibaraki Prefecture. We collected mud sediment in the aquatic areas at Stns. $1-8$ and $10-12$ and seawater at Stn. 9. Table 1 presents the values of $\mathrm{pH}, \mathrm{NaCl}$ concentration, and water temperature at each sampling area and the isolation of yeast-like colonies. The $\mathrm{pH}$ ranges of the samples were around $7-8$, and the highest $\mathrm{pH}$ values were observed at Stn. 3; the branch junction of the river and Stn. 12; and in the lake (pH $8.80-8.81$ ). With the sampling from 12 sites, we isolated 1028 yeast-like strains. 
(a)

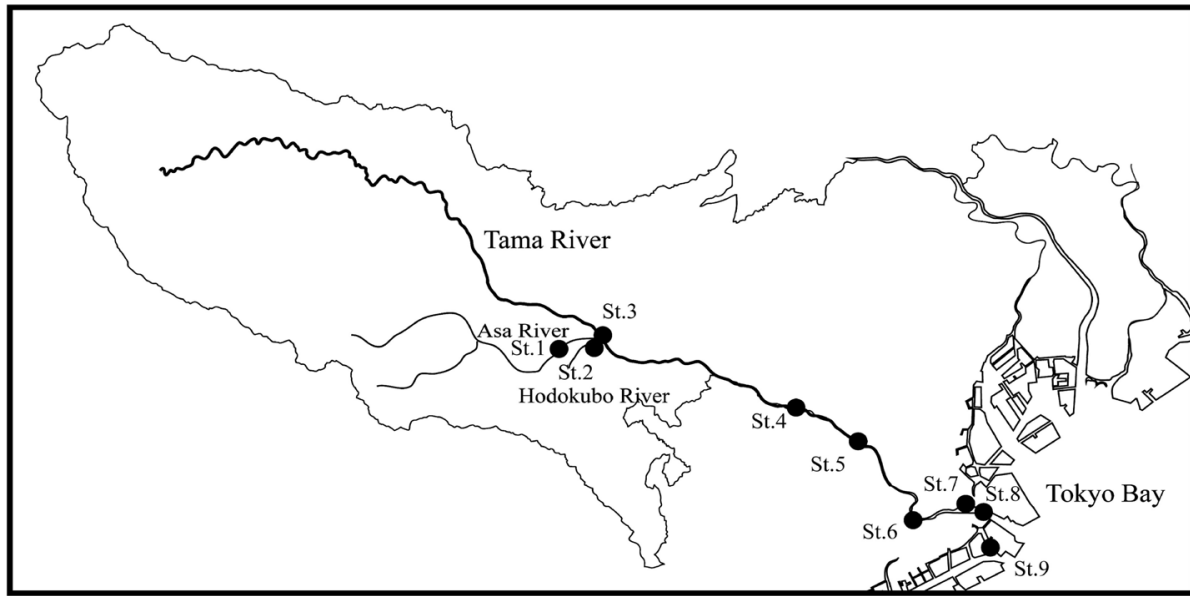

(b)

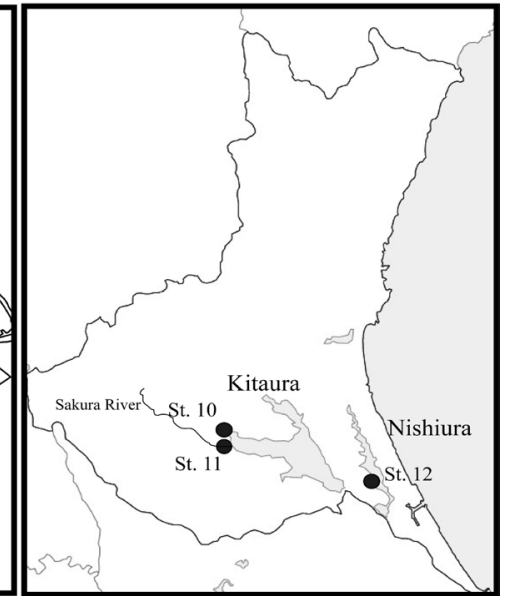

Figure 1. Location of sampling sites. (a) Tama River, Tokyo. (b) Lake Kasumigaura, Ibaraki.

Table 1. $\mathrm{pH}, \mathrm{NaCl}$ concentration, and water temperature of each sampling area \& number of all isolated yeast strains and fermentative ones in each stress medium.

\begin{tabular}{|c|c|c|c|c|c|c|c|c|c|c|c|c|}
\hline \multirow{2}{*}{$\begin{array}{c}\text { Sampling } \\
\text { No. }\end{array}$} & \multirow{2}{*}{\multicolumn{3}{|c|}{ Sampling area }} & \multirow[b]{2}{*}{$\mathrm{pH}$} & \multirow{2}{*}{$\begin{array}{c}\mathrm{NaCl} \\
(\%)\end{array}$} & \multirow{2}{*}{$\begin{array}{c}\text { Water } \\
\text { temperature } \\
\left({ }^{\circ} \mathrm{C}\right)\end{array}$} & \multirow{2}{*}{$\begin{array}{c}\text { No. of } \\
\text { isolation }\end{array}$} & \multicolumn{5}{|c|}{ Gas production } \\
\hline & & & & & & & & & YPD + & YPD + & $\begin{array}{c}\text { YPD + } \\
20 \%\end{array}$ & $\begin{array}{c}\text { YPD + } \\
30 \%\end{array}$ \\
\hline Station 1 & & Asa River & Mud & 8.19 & 0.00 & 26.5 & 217 & 18 & 16 & 1 & 1 & 1 \\
\hline Station 2 & $\begin{array}{l}\text { Tama River } \\
\text { midstream }\end{array}$ & Hodokubo River & Mud & 8.63 & 0.00 & 27.0 & 100 & 49 & 46 & 2 & 1 & 1 \\
\hline Station 3 & & Branch Junction & Mud & 8.80 & 0.01 & 25.8 & 165 & 30 & 28 & 6 & 4 & 4 \\
\hline $\begin{array}{c}\text { Stations } \\
1-3\end{array}$ & & & & & & & 482 & 97 & 90 & 9 & 6 & 6 \\
\hline Station 4 & & Rokugo Bank & Mud & 6.91 & 0.86 & 23.5 & 80 & 33 & 24 & 2 & 0 & 0 \\
\hline Station 5 & $\begin{array}{l}\text { Tama River } \\
\text { downstream }\end{array}$ & Futakotama River.1 & Mud & 7.36 & 0.01 & 21.2 & 90 & 32 & 25 & 9 & 8 & 8 \\
\hline Station 6 & & Futakotama River.2 & Mud & 7.53 & 0.03 & 25.0 & 20 & 12 & 8 & 4 & 0 & 0 \\
\hline $\begin{array}{c}\text { Stations } \\
4-6\end{array}$ & & & & & & & 190 & 77 & 57 & 15 & 8 & 8 \\
\hline Station 7 & & Anamori Inari.1 & Mud & 7.93 & 0.37 & 27.0 & 51 & 37 & 33 & 7 & 6 & 4 \\
\hline Station 8 & $\begin{array}{l}\text { Tama River } \\
\text { estuary }\end{array}$ & Anamori Inari. 2 & Mud & 7.81 & 0.26 & 28.5 & 87 & 60 & 56 & 19 & 18 & 6 \\
\hline Station 9 & & Chidori Park & Water & 8.49 & 3.20 & 28.5 & 33 & 16 & 16 & 4 & 4 & 0 \\
\hline $\begin{array}{c}\text { Stations } \\
7-9\end{array}$ & & & & & & & 171 & 113 & 105 & 30 & 28 & 10 \\
\hline Station 10 & & Sakura River & Mud & 7.74 & 0.00 & 21.5 & 64 & 61 & 61 & 4 & 3 & 1 \\
\hline Station 11 & $\begin{array}{c}\text { Lake } \\
\text { Kasumigaura }\end{array}$ & Nishiura & Mud & 7.89 & 0.39 & 22.0 & 76 & 45 & 45 & 16 & 5 & 3 \\
\hline Station 12 & & Kitaura & Mud & 8.81 & 0.02 & 22.0 & 45 & 19 & 19 & 9 & 4 & 3 \\
\hline $\begin{array}{c}\text { Stations } \\
10-12\end{array}$ & & & & & & & 185 & 125 & 125 & 29 & 12 & 7 \\
\hline Total & & & & & & & 1028 & 412 & 377 & 83 & 54 & 31 \\
\hline
\end{tabular}




\subsection{The Screening of Fermentative Yeasts with Tolerance against Sorbitol and Ethanol}

Table 1 provides the numbers of all of the isolated yeast strains and the fermentative strains in each medium. With the first screening of strains from Stns. 1 - 3 with YPD liquid medium, 482 strains were isolated as yeast-like microorganisms, and 97 strains were isolated as fermentative microorganisms. From Stns. 4 - 6, 77 strains among all 190 isolates were fermentative. From Stns. 7 - 9, 113 strains of the 171 isolates were fermentative. From Stns. $10-12,125$ strains of the 185 isolates were fermentative. Thus, 412 strains from all 12 of the stations were fermentative.

The second screening with YPD liquid medium containing 30\% (w/v) sorbitol was carried out, and 377 strains (from all of the stations) were fermentative. These results revealed that approx. $91.5 \%$ of the fermentative strains identified by the first screening showed tolerance against $30 \%(\mathrm{w} / \mathrm{v})$ sorbitol.

With the third screening with the medium containing $10 \%(\mathrm{v} / \mathrm{v})$ ethanol, only 83 strains (approx. 20.1\% of the strains in the first screening) exhibited tolerance against ethanol stress. Eventually, by the fifth screening, 31 strains (approx. 7.5\% of the strains from the first screening) were confirmed as having tolerance against both $30 \%(\mathrm{w} / \mathrm{v})$ sorbitol and $10 \%(\mathrm{v} / \mathrm{v})$ ethanol.

\subsection{Identification of the 31 Strains with Tolerance to Various Stresses \& the Screening of Fermentative Yeasts with Tolerance to $\mathrm{NaCl}$}

We further analyzed the 31 selected yeast strains and confirmed the six species of these strains. The largest number of strains $(\mathrm{n}=10)$ was identified as Wickerhamomyces anomalus: AN1-46 (from Stn. 7); AN2-9, AN2-56, and AN2-64 from Stn. 8; KS28, KS51, and KS75 from Stn. 11; and KN8, KN9, and KN43 from Stn. 12. W. anomalus was previously isolated as an alkali-tolerant yeast in our laboratory [16], and in the present study, we isolated $W$. anomalus from Stn. 7 (pH 7.93), Stn. 8 (pH 7.81), Stn. 11 (pH 7.89), and Stn. 12 (pH 8.81).

Eight yeast strains were identified as Torulaspola delbruekii: AS183 from Stn. 1, and F2-2, F2-11, F2-24, F2-36, F2-41, F2-63, and F2-82 from Stn. 5. As shown in Table 2, both the $W$. anomalus strains and the $T$. delbrueckii strains exhibited tolerance against $15 \%(\mathrm{w} / \mathrm{v}) \mathrm{NaCl}$.

Six strains were identified as Candida glabrata: TC18 and TC140 from Stn. 2; AN1-25 from Stn. 7 and AN2-49, AN2-54, and AN2-58 from Stn. 8. Four of these strains (TC18, AN2-49, AN2-54 and AN2-58) also had high tolerance against $15 \%(w / v) ~ N a C l$. Although $C$. glabrata is known to be evolutionally very closely related to baker's yeast (which has high fermentation activity under salt pressure), C. glabrata is a pathogenic yeast, and it was thought to need special handling [17].

Four strains were identified as Pichia kudriavzevii: TC47 and TC106 from Stn. 2 and AN1-13 and AN1-19 from Stn. 7. Strain H28 (from Stn. 3) was identified as Saccharomyces cf. cerevisiael paradoxus, and strains F2-67 (from Stn. 5) and 
Table 2. Results of identification for 31 strains of environmental yeasts \& fermentation activities of 31 strains with tolerance against sorbitol and ethanol under $\mathrm{NaCl}$.

\begin{tabular}{|c|c|c|c|c|c|c|c|}
\hline Sampling area & Strain & Identification result & Identity (\%) & Accession No. & $5 \% \mathrm{NaCl}$ & $10 \% \mathrm{NaCl}$ & $15 \% \mathrm{NaCl}$ \\
\hline Station 1 & AS183 & Torulaspora delbrueckii & 99 & LC506482 & ++ & ++ & + \\
\hline \multirow{5}{*}{ Station 2} & TC18 & & 99 & LC506483 & ++ & ++ & ++ \\
\hline & TC140 & Candida glabrata & 100 & IC506486 & ++ & ++ & - \\
\hline & & & & & & & \\
\hline & TC47 & Dichin lundrimancii & 99 & LC506484 & ++ & ++ & - \\
\hline & TC106 & 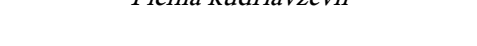 & 99 & LC506485 & ++ & ++ & + \\
\hline \multirow[t]{4}{*}{ Station 3} & $\mathrm{H} 28$ & Saccharomyces cf. cerevisiael paradoxus & 99 & LC506487 & ++ & ++ & - \\
\hline & $\mathrm{F} 2-2$ & & 100 & LC506474 & ++ & ++ & ++ \\
\hline & $\mathrm{F} 2-11$ & & 99 & LC506475 & ++ & ++ & ++ \\
\hline & $\mathrm{F} 2-24$ & & 100 & LC506476 & ++ & ++ & ++ \\
\hline \multirow{5}{*}{ Station 5} & F2-36 & Torulaspora delbrueckii & 99 & LC506477 & ++ & ++ & ++ \\
\hline & $\mathrm{F} 2-41$ & & 99 & LC506478 & ++ & ++ & ++ \\
\hline & $\mathrm{F} 2-63$ & & 99 & LC506479 & ++ & ++ & ++ \\
\hline & $\mathrm{F} 2-82$ & & 99 & LC506481 & ++ & ++ & - \\
\hline & $\mathrm{F} 2-67$ & Lachancea kluyveri & 100 & LC506480 & ++ & ++ & ++ \\
\hline \multirow{6}{*}{ Station 7} & AN1-13 & & 100 & LC506488 & ++ & ++ & - \\
\hline & AN1-19 & Pichia kudriavzevii & 100 & LC506489 & ++ & ++ & - \\
\hline & AN1-25 & Candida glabrata & 99 & LC506490 & ++ & ++ & - \\
\hline & AN1-46 & Wickerhamomyces anomalus & 99 & LC506491 & ++ & ++ & ++ \\
\hline & AN2-49 & & 100 & LC506493 & ++ & ++ & ++ \\
\hline & AN2-54 & Candida glabrata & 99 & LC506494 & ++ & ++ & ++ \\
\hline \multirow{4}{*}{ Station 8} & AN2-58 & & 99 & LC506496 & ++ & ++ & ++ \\
\hline & AN2-9 & & 100 & LC506492 & ++ & ++ & - \\
\hline & AN2-56 & Wickerhamomyces anomalus & 99 & LC506495 & ++ & ++ & + \\
\hline & AN2-64 & & 99 & LC506497 & ++ & ++ & ++ \\
\hline \multirow[t]{2}{*}{ Station 10} & S11 & Lachancea kluyveri & 99 & LC506498 & ++ & ++ & - \\
\hline & KS28 & & 100 & LC506499 & ++ & ++ & + \\
\hline \multirow[t]{3}{*}{ Station 11} & KS51 & & 100 & LC506500 & ++ & ++ & ++ \\
\hline & KS75 & & 97 & LC506501 & ++ & ++ & ++ \\
\hline & KN8 & 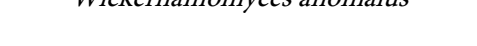 & 100 & LC506502 & ++ & ++ & ++ \\
\hline \multirow[t]{2}{*}{ Station 12} & KN9 & & 100 & LC506503 & ++ & ++ & ++ \\
\hline & KN43 & & 100 & LC506504 & ++ & ++ & ++ \\
\hline
\end{tabular}

++: High fermentation activity, +: Fermentation activity, -: Not detected fermentation activity. High fermentation activity: Inverted Durham tubes were filled with gas within 3 days. Fermentation activity: Confirmed gas visualized within 2 weeks.

S11 (from Stn. 10) were identified as Lachancea kluyveri. Among these yeasts, $S$. cf. cerevisiael paradoxus, $P$. kudriavzevii and $L$. kluyveri had no tolerance against $15 \%(\mathrm{w} / \mathrm{v}) \mathrm{NaCl}$. None of the yeasts showed tolerance against $20 \%(\mathrm{w} / \mathrm{v}) \mathrm{NaCl}$. 


\subsection{Ethanol Production by the 31 Selected Strains}

We conducted the fermentation of the 31 selected strains in YPD liquid medium as shown in Figure 2. Strain F2-11 showed the highest ethanol production among the eight strains of $T$. delbrueckii: $14.80 \mathrm{~g} / \mathrm{L}$. Of the 10 strains of $W$. anomalus, the highest ethanol production was by strain AN2-56 at $13.86 \mathrm{~g} / \mathrm{L}$. Of the two L. kluyveri strains, F2-67 provided the highest ethanol production; 12.46 g/L. Of the six strains of $C$. glabrata, TC18 had the highest ethanol production at $12.55 \mathrm{~g} / \mathrm{L}$. Of the four $P$. kudriavzevii strains, AN1-13 showed the highest ethanol production; $11.26 \mathrm{~g} / \mathrm{L}$. The $S$. cf. cereivisael paradoxus strain $\mathrm{H} 28$ produced ethanol at $7.61 \mathrm{~g} / \mathrm{L}$, which seemed to be relatively lower than those of the other species. We thus selected the strain with the highest productivity in each species (except for $W$. anomalus) and conducted the next fermentation experiment using molasses as described above in Section 3.5. In the case of W. anomalus, we used strain AN2-64 as described in Section 3.5 because the $\mathrm{NaCl}$ tolerance of strain AN2-64 was higher than that of strain AN2-56.

\subsection{Sugar Consumption and Ethanol Production from Molasses by the Representative Strains of the Six Species}

We conducted fermentation experiments with each representative strain of the six species in $25 \%(\mathrm{w} / \mathrm{v})$ diluted molasses with the following sugar composition: sucrose $104.0 \mathrm{~g} / \mathrm{L}$, fructose $33.4 \mathrm{~g} / \mathrm{L}$, and glucose $24.8 \mathrm{~g} / \mathrm{L}$. Figure 3 illustrates the changes in the sugar concentration by each representative strain of the six species before and after fermentation in the molasses. For the $S$. cf. cereivisael paradoxus strain $\mathrm{H} 28$, the L. kluyveri strain F2-67, the T. delbrueckii strain F2-11, and the $W$. anomalus strain AN2-64, the level of sucrose in the molasses decreased remarkably; the activities of invertase secreted from their cells would be high. Most notably, in S. cf. cereivisael paradoxus H28 and L. kluyveri F2-67, most of the glucose and fructose were consumed by these yeast strains, and thus the fermentation activity may be high.

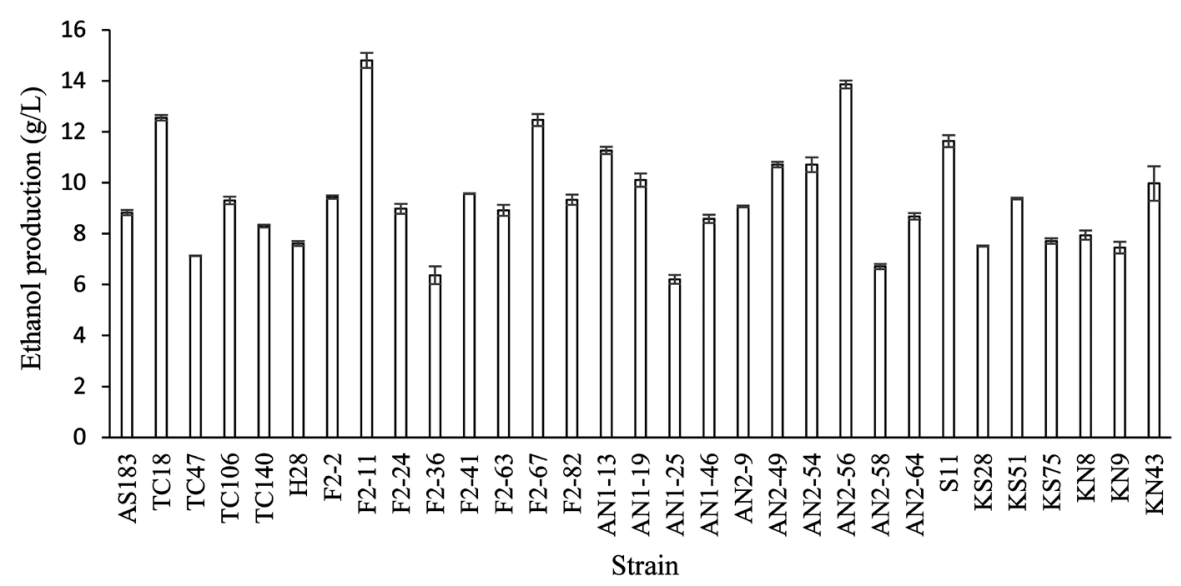

Figure 2. Ethanol production by the 31 selected yeast strains after fermentation in the YPD medium. The bar graph values are the mean of triplicate trials, with their standard deviation $(\mathrm{SD})$ values. 
Figure 4 shows the ethanol production by each representative strain of the six species after the fermentation in molasses. Among the six strains, the ethanol production by two was high in proportion to the sugar consumption: $S$. cf. cereivisael paradoxus $\mathrm{H} 28$ produced ethanol at $57.4 \mathrm{~g} / \mathrm{L}$, and L. kluyveri F2-67 produced ethanol at $53.9 \mathrm{~g} / \mathrm{L}$.

\section{Discussion}

We conducted this study with the larger goal of producing an effective bioethanol production system based on the use of yeast. We succeeded in isolating six yeast species that have both stress tolerance and high fermentation activities. Among them, the $S$. cf. cerevisiael paradoxus strain $\mathrm{H} 28$ showed superior

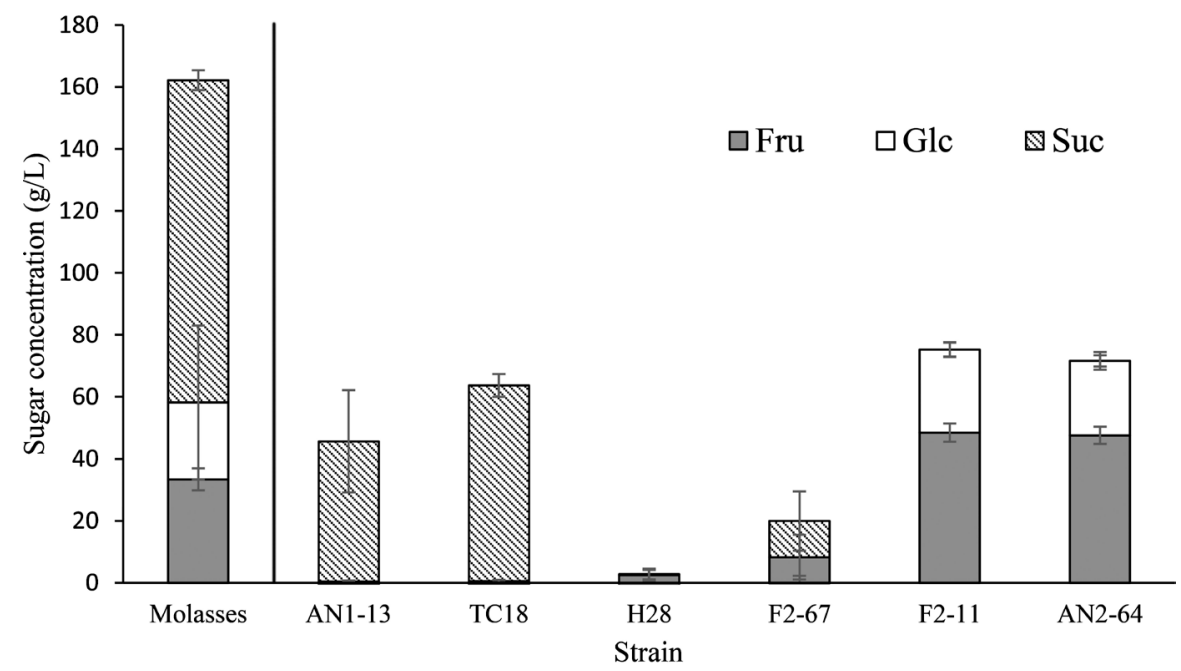

Figure 3. The sugar concentration in the molasses and residual sugar concentration after fermentation by the six representative strains. The bar graph values are the mean of triplicate trials, with their standard deviation (SD) values.

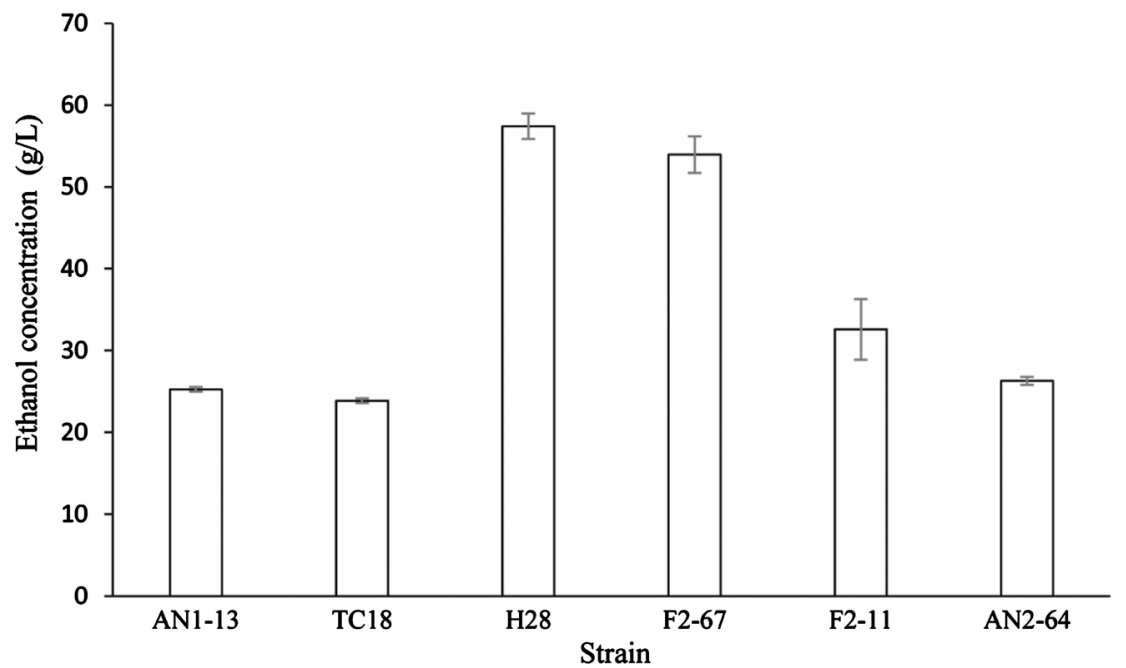

Figure 4. Ethanol productions by the six representative strains after fermentation in the molasses. The bar graph values are the mean of triplicate trials, with their standard deviation (SD) values. 
fermentation activity with molasses (as described above in Section 3.5), and its fermentation ability is closely related to the values obtained in our previous studies [7] [8] [9] [11] [12] [14]. The results of our present investigation suggest that $W$. anomalus, $T$. delbrueckii, and $C$. glabrata have superior osmotic tolerance (as shown in Section 3.3). Both W. anomalus and T. delbrueckii are used for wine making in some countries [18] [19], suggesting that these yeasts have tolerance against high concentrations of alcohol.

W. anomalus, which is also known as Pichia anomala and Hansenula anomala, is frequently associated with spoilage or the processing of food and grain products. Its capacity for growth on a wide range of carbon sources at low $\mathrm{pH}$, under high osmotic pressure, and with little or no oxygen enables $W$. anomalus to propagate in a wide range of environments [20]. It is a non-Saccharomyces wine yeast that contributes to wine aroma through the production of volatile compounds. T. delbrueckii has also been isolated from several human bioprocesses including in the bread and wine industries, and it was thought to be a spoilage yeast contaminating high-osmotic liquids [21].

As shown in Figure 2, the fermentation efficiencies of both $W$. anomalus and T. delbrueckii were superior to that of $S$. cerevisiae, depending on the culture conditions. To establish the suitability of the stress-tolerant yeasts identified in this study for industrial processes, further studies must be performed to determine the details of the optimal fermentation conditions.

\section{Conclusion}

We isolated 31 yeast strains with high fermentation ability under the stress conditions in medium containing 30\% (w/v) sorbitol and 10\% (v/v) ethanol from natural aquatic environments: Tama River and Lake Kasumigaura in Japan. Among these yeast strains, Torulaspora delbrueckii, Wickerhamomyces anomalus, and Candida glabrata exhibited tolerance against 15\% (w/v) NaCl. Most notably, the Saccharomyces cf. cerevisiael paradoxus strain $\mathrm{H} 28$ and the Lachancea kluyveri strain $\mathrm{F} 2-67$ produced $57.4 \mathrm{~g} / \mathrm{L}$ and $53.9 \mathrm{~g} / \mathrm{L}$ ethanol with molasses (sucrose $104.0 \mathrm{~g} / \mathrm{L}$, fructose $33.4 \mathrm{~g} / \mathrm{L}$, and glucose $24.8 \mathrm{~g} / \mathrm{L}$ ) within $48 \mathrm{hrs}$, respectively.

\section{Conflicts of Interest}

The authors declare no conflicts of interest regarding the publication of this paper.

\section{References}

[1] Álvarez-Cao, M.E., Cerdán, M.E., González-Siso, M.I. and Becerra, M. (2019) Bioconversion of Beet Molasses to Alpha-Galactosidase and Ethanol. Frontiers in Microbiollogy, 10, 450. https://doi.org/10.3389/fmicb.2019.00405

[2] Arshad, M., Hussain, T., Iqbal, M. and Abbas, M. (2015) Enhanced Ethanol Production at Commercial Scale from Molasses Using High Gravity Technology by Mutant S. cerevisiae. Brazilian Journal of Microbiology, 48, 403-409. 
https://doi.org/10.1016/j.bjm.2017.02.003

[3] Ueno, R., Urano, N. and Kimura, S. (2001) Characterization of Thermotolerant, Fermentative Yeasts from Hot Spring Drainage. Fisheries Science, 67, 138-145. https://doi.org/10.1046/j.1444-2906.2001.00210.x

[4] Ueno, R., Urano, N., Suzuki, M. and Kimura, S. (2002) Isolation, Characterization, and Fermentative Pattern of a Novel Thermotolerant Prototheca zopfii var. hydrocarbonea Strain Producing Ethanol and $\mathrm{CO}_{2}$ from Glucose at $40^{\circ} \mathrm{C}$. Archives of Microbiology, 177, 244-250. https://doi.org/10.1007/s00203-001-0384-0

[5] Ueno, R., Urano, N. and Kimura, S. (2002) Effect of Temperature and Cell Density on the Ethanol Fermentation by a Thermotolerant, Aquatic Yeast Strain Isolated from Hot Spring Environment. Fisheries Science, 68, 571-578.

https://doi.org/10.1046/j.1444-2906.2002.00463.x

[6] Ueno, R., Hamada-Sato, N. and Urano, N. (2003) Fermentation of Molasses by Several Yeasts from Hot Spring Drain and Phylogeny of the Unique Isolate Producing Ethanol at $55^{\circ} \mathrm{C}$. Journal of the Tokyo University of Fisheries, 90, 23-30.

[7] Ogawa, G., Ishida, M., Usui, Y. and Urano, N. (2008) Ethanol Production from the Water Hyacinth Eichhornia crassipes by Yeast Isolated from Various Hydrospheres. African Journal of Microbiology Research, 2, 110-113.

[8] Takagi, T., Uchida, M., Matsushima, R., Ishida, M. and Urano, N. (2012) Efficient Bioethanol Production from Water Hyacinth Eichhornia crassipes by Both Preparation of the Saccharified Solution and Selection of Fermenting Yeasts. Fisheries Science, 78, 905-910. https://doi.org/10.1007/s12562-012-0516-2

[9] Obara, N., Ishida, M., Hamada-Sato, N. and Urano, N. (2012) Efficient Bioethanol Production from Paper Shredder Scrap by a Marine Derived Saccharomyces cerevisiae C-19. Studies Science \& Technology, 1, 49-54.

[10] Uchida, M., Miyoshi, T., Kaneniwa, M., Ishihara, K., Nakashimada, Y. and Urano, N. (2014) Production of $16.5 \% \mathrm{v} / \mathrm{v}$ Ethanol from Seagrass Seeds. Journal of Bioscience and Bioengineering, 118, 646-650. https://doi.org/10.1016/j.jbiosc.2014.05.017

[11] Obara, N., Okai, M., Ishida, M. and Urano, N. (2015) Bioethanol Production from Mixed Biomass (Waste of Undaria pinnatifida Processing and Paper Shredding) by Fermentation with Marine-Derived Saccharomyces cerevisiae. Fisheries Science, 81, 771-776. https://doi.org/10.1007/s12562-015-0877-4

[12] Takagi, T., Uchida, M., Matsushima, R., Komada, H., Takeda, T., Ishida, M. and Urano, N. (2015) Comparison of Ethanol Productivity among Yeast Strains Using Three Different Seaweeds. Fisheries Science, 81, 763-770. https://doi.org/10.1007/s12562-015-0875-6

[13] Okai, M., Betsuno, A., Shirao, A., Obara, N., Suzuki, K., Takei, T., Takashio, M., Ishida, M. and Urano, N. (2017) Citeromyces matritensis M37 Is a Salt Tolerant Yeast That Produces Ethanol from Salted Algae. Canadian Journal of Microbiology, 63, 20-26. https://doi.org/10.1139/cjm-2016-0259

[14] Urano, N., Shirao, A., Okai, M. and Ishida, M. (2017) High Ethanol Production by Marine-Derived Yeasts-Saccharomyces cerevisiae under Stress Pressures. Advances in Microbiology, 7, 348-357. https://doi.org/10.4236/aim.2017.75029

[15] Atiyeh, H. and Duvnjak, Z. (2008) Production of Fructose and Ethanol from Sugar Beet Molasses Using Saccharomyces cerevisiae ATCC 36858. Biotechnology Progress, 18, 234-239. https://doi.org/10.1021/bp010164z

[16] Urano, N., Shirao, A., Naito, Y., Okai, M., Ishida, M. and Takashio, M. (2019) Molecular Phylogeny and Phenotypic Characterization of Yeasts with a Broad Range of 
pH Tolerance Isolated from Natural Aquatic Environments. Advances in Microbiology, 9, 56-73. https://doi.org/10.4236/aim.2019.91005

[17] Bialkova, A. and Subic, J. (2006) Biology of the Pathogenic Yeast Candia glabrata. Folia Microbiologica, 51, 3-20. https://doi.org/10.1007/BF02931443

[18] Van Breda, V., Jolly, N. and van Wyk, J. (2012) Characterization of Commercial and Natural Torulaspora delbrueckii Wine Yeast Strains. International Journal of Food Microbiology, 163, 80-88. https://doi.org/10.1016/j.ijfoodmicro.2013.02.011

[19] Padilla, B., Gil, J.V. and Manzanares, P. (2018) Challenges of the Non-Conventional Yeast Wickerhamomyces anomalus in Winemaking. Fermentation, 4, 68. https://doi.org/10.3390/fermentation4030068

[20] Passoth, V., Fredlund, E., Druvefors, U.A. and Schnurer, J. (2006) Biotechnology, Physiology and Genetics of the Yeast Pichia anomala. FEMS Yeast Research, 6, 3-13. https://doi.org/10.1111/j.1567-1364.2005.00004.x

[21] Albertin, W., Chasseriaud, L., Comte, G., Panfili, A., Delcamp, A., Salin, F., Marullo, P. and Bely, M. (2014) Winemaking and Bioprocesses Strongly Shaped the Genetic Diversity of the Ubiquitous Yeast Torulaspora delburueckii. PLoS ONE, 9, e94246. https://doi.org/10.1371/journal.pone.0094246 